\title{
Designing a model to minimize inequities in hemodialysis facilities distribution
}

\author{
Teresa M. Salgado', Rebekah Moles², Shalom I. Benrimoj², Fernando Fernandez-Llimos ${ }^{3}$ \\ ${ }^{1}$ Research Institute for Medicines and Pharmaceutical Sciences, Faculty of Pharmacy, University of Lisbon, \\ Portugal; ${ }^{2}$ Faculty of Pharmacy, University of Sydney, NSW, Australia; ${ }^{3}$ Department of Social Pharmacy, \\ Faculty of Pharmacy, University of Lisbon, Portugal
}

\begin{abstract}
Portugal has an uneven, city-centered bias in the distribution of hemodialysis centers found to contribute to health care inequities. A model has been developed with the aim of minimizing access inequity through the identification of the best possible localization of new hemodialysis facilities. The model was designed under the assumption that individuals from different geographic areas, ceteris paribus, present the same likelihood of requiring hemodialysis in the future. Distances to reach the closest hemodialysis facility were calculated for every municipality lacking one. Regions were scored by aggregating weights of the "individual burden", defined as the burden for an individual living in a region lacking a hemodialysis center to reach one as often as needed, and the "population burden", defined as the burden for the total population living in such a region. The model revealed that the average travelling distance for inhabitants in municipalities without a hemodialysis center is $32 \mathrm{~km}$ and that 145,551 inhabitants $(1.5 \%)$ live more than $60 \mathrm{~min}$ away from a hemodialysis center, while $1,393,770(13.8 \%)$ live 30-60 min away. Multivariate analysis showed that the current localization of hemodialysis facilities is associated with major urban areas. The model developed recommends 12 locations for establishing hemodialysis centers that would result in drastically reduced travel for 34 other municipalities, leaving only six (34,800 people) with over 60 min of travel. The application of this model should facilitate the planning of future hemodialysis services as it takes into consideration the potential impact of travel time for individuals in need of dialysis, as well as the logistic arrangements required to transport all patients with end-stage renal disease. The model is applicable in any country and health care planners can opt to weigh these two elements differently in the model according to their priorities.
\end{abstract}

Keywords: renal dialysis, health services accessibility, healthcare disparities, policy-making, Portugal.

\section{Introduction}

According to international guidelines for hemodialysis, the standard protocol is to dialyze for three to five hours, three times a week (ERA-EDTA, 2002; NKF, 2006). Prevalence of end-stage renal disease (ESRD) in Portugal was 961 per million population in 2009. Twenty-five percent of these patients commenced hemodialysis due to diabetes, $16 \%$ as a result of hypertension, whereas in $22 \%$ of the cases the etiology of dialysis initiation was unable to be determined (Sociedade Portuguesa de Nefrologia, 2009b). The quality of life in patients with ESRD is severely impaired and significantly lower than that of the healthy population (Sayin et al., 2007). Additionally, travel time to the hemodialysis facility can represent a substantial burden for many patients. In qualitative

\footnotetext{
Corresponding author:

Fernando Fernandez-Llimos

Department of Social Pharmacy, Faculty of Pharmacy

University of Lisbon

Avenida Prof. Gama Pinto, 1649-003 Lisbon, Portugal

Tel. +351 217946 400; Fax+351 217946470

E-mail: f-llimos@ff.ul.pt
}

research studies, patients expressed the need of living close to a dialysis facility (Harwood et al., 2005), besides manifesting the feeling of life revolving around dialysis (Krespi et al., 2004), and struggling with a time-consuming care (Hagren et al., 2005). A study determining distances travelled and time spent in transport among hemodialysis patients living in a Scottish rural area, concluded that $19 \%$ of the patients travelled in excess 100 miles $(160 \mathrm{~km})$ per dialysis day, corresponding to 15,000 miles $(24,000 \mathrm{~km})$ per year (Brammah et al., 2001). In Wales, $20.3 \%$ of people live 30-60 min away from a hemodialysis center, and $2.1 \%$ of the population would need $60 \mathrm{~min}$ or more to reach the closest center (White et al., 2006). Similar travel times were reported in the Dialysis Outcomes and Practice Patterns Study, which showed that $22.4 \%$ of the 10,219 hemodialysis patients who participated in the study live 30-60 min away from a center and $5.2 \%$ were more than $60 \mathrm{~min}$ away (Moist et al., 2008). Although Portugal did not participate in this particular study, Spain, which has similar socioeconomic characteristics as Portugal, reported that $30.0 \%$ of patients undergoing hemodialysis live 30-60 min from a facility and $11.8 \%$ more than one hour away. 
Aiming to reduce the burden of travel, the Scottish Government established the goal that all patients should be able to access a hemodialysis unit from their homes within $30 \mathrm{~min}$ (NHS-Scotland, 2002). However, later data reveal that $10 \%$ of patients undergoing renal replacement therapy in Scotland live more than $30 \mathrm{~min}$ away from a center (MacGregor et al., 2005).

Patients living 60 min away from a hemodialysis center not only run increased risk of mortality (Relative Risk $=1.2$ ), but have also a significantly lower quality of life compared to patients living 15 min or less away (Moist et al., 2008). It has been reported that there is an inverse relation of initiation of renal replacement therapy with distance (Roderick et al., 1999) and that referral of patients with ESRD, aged 60 years and over, decrease with distance to the treatment center (Boyle et al., 1996). This fact was confirmed by another study which found that the prevalence of renal replacement therapy fell significantly with longer travel times for dialysis, even when patients lived relatively close to a facility (White et al., 2006).

Geospatial analytical techniques have been used in several areas of public health and policy making to optimize health care resources. One study used geospatial information and techniques to analyse relationships between services, capacity, catchment distance and population distribution to improve decision-making in the planning of health services (Lwasa, 2007). Another study described a geospatial model to estimate potential catchment areas around health facilities based on access travel time (Hernandez-Avila et al., 2010). An ambulance deployment strategy based on geospatial-time analysis was able to reduce ambulance response times for out-of-hospital cardiac arrests in an urban emergency medical services system (Ong et al., 2010). Several studies have presented models based on geographical information systems (GIS) to identify the best localization of hemodialysis facilities based on the number of patients currently undergoing hemodialysis and the distance travelled for treatment (MacGregor et al., 2005; White et al., 2006). The World Health Organization (WHO) is concerned about equity in the provision of renal replacement therapy (White et al., 2008) but, to our knowledge, no model has been designed to estimate the potential impact of future centers on the incidence of renal replacement therapy. Predicting future facilities using point prevalence data may not be accurate, since it has been shown that prevalence fell significantly with increasing travel time from treatment units (White et al., 2006).
The travel time to reach a hemodialysis facility is an important issue for ESRD patients. The aim of this work was to find a model that could minimize inequity in access to treatment by facilitating the identification of superior locations for new hemodialysis units. We used a probabilistic approach that assumed that individuals from different geographical areas, ceteris paribus, present the same probability of needing hemodialysis in the future.

\section{Materials and methods}

\section{Analysis of Portuguese data}

In Portugal, dialysis provision for outpatients is mostly private, with only patients who are hemodynamically unstable being treated in public hospitals. Data on the geographical distribution of existing hemodialysis centers in Portugal mainland, both public and private, were obtained (30 June 2009) from the Portuguese Society of Nephrology (Sociedade Portuguesa de Nefrologia, 2009a). The populations in the various Portuguese administrative regions was collected from the National Institute of Statistics (INE, 2009b). In addition, a number of other covariates such as buying power percentage, electricity consumption, distance to the closest hemodialysis center by municipality and by geographic region (INE, 2009a,c) were used in the analysis. Buying power percentage reflects the relative weight of the purchasing power for each municipality compared to the total of the country, which represents $100 \%$, and can be used as a proxy for individuals' wealth. Electricity consumption per inhabitant $(\mathrm{kWh} /$ inhabitant) was used as an indicator of industrialization. In 2003, Portugal adopted the European regulation on Nomenclature of Territorial Units for Statistics (NUTS). This is a hierarchical classification which divides each European Union Member State into three administrative levels. Portugal mainland, Madeira, and Azores constitute the three NUTS-1 regions in Portugal. The mainland is divided into five NUTS-2 regions: North, Central, Lisbon \& Tagus Valley, Alentejo and Algarve, which are together divided into 28 NUTS-3 levels consisting of 278 municipalities (European Commission, 2003). To investigate associations between the existence of a hemodialysis center (either public or private) in a given municipality and potential covariates, a univariate analysis (non-parametric tests) and a logistic regression were performed using SPSS version 16 (http://www.spss.com). 


\section{Development of the model}

For the modeling purposes discussed here, the municipality level was used. A probabilistic approach was used assuming that individuals from different geographic areas, ceteris paribus, presented the same likelihood of needing hemodialysis in the future. This assumption was based on the fact that no evidence of spatial or geographical determinants for ESRD was found. In addition, no such determinants were reported for diabetes, one of the main causes of ESRD. Although, one study reported differences in the prevalence of hypertension across the five NUTS-2 regions in Portugal (de Macedo et al., 2007), these data were not taken into account, since they may be affected by further inequities in the health care distribution in the country (Oliveira and Bevan, 2003).

The distances to reach the closest hemodialysis facility were calculated for every municipality lacking one. This was done via the Internet at the Michelin Portugal website (Michelin, 2009) using the available options "quicker way" and "avoid tolls". The "individual burden" was defined as the potential burden for one individual living in a municipality lacking a hemodialysis center, which was set as equal to the driving time to the closest hemodialysis facility. The "population burden" was defined in the same way but taking the total municipal population into account. It was calculated by multiplying the number of people living in a given municipality by the driving time to the closest facility.

Quartiles for the "population burden" and the "individual burden" distributions were calculated and scores assigned to each municipality from 1 (first quartile) to 4 (fourth quartile). In addition, maps for both distributions were drawn. To create a "composite burden" map, scores assigned to each municipality in both distributions were added together, and categories for the aggregated scores divided into 2-3, 4-5, 6-7 and 8 , the latter considered as the best potential location of a new hemodialysis center, since it represents the greatest composite burden (individual burden = 4; population burden $=4$; composite burden $=8$ ) .

\section{Results}

\section{Identifying necessities}

Based on the availability of 111 hemodialysis facilities in Portugal mainland (Sociedade Portuguesa de Nefrologia, 2009a) and a total population of $10,126,880$ (INE, 2009b), the ratio of hemodialysis center per inhabitant was estimated at 91,233. The information from the Portuguese Society of Nephrology revealed that out of 278 municipalities of Portugal mainland, $215(77.3 \%)$ are completely devoid of hemodialysis centers, $47(16.9 \%)$ have only one, nine $(3.2 \%)$ have two and three municipalities $(1.1 \%)$ have three centers, respectively. Lisbon, Oporto and Coimbra, the three major cities in Portugal, have 15, 11 and 7 centers, with an average of 33,313, 20,163 and 19,601 inhabitants per center, respectively. Table 1 presents the distribution of hemodialysis centers in Portugal mainland aggregated by NUTS-2. The 215 municipalities lacking hemodialysis centers together account for $3,824,793$ inhabitants $37.8 \%$ of population in Portugal mainland), with an average population of 17,790 people (standard deviation $(\mathrm{SD})=16,482$ ). The average population in municipalities lacking hemodialysis centers is not homogeneously distributed across regions (Kruskal-Wallis test; $\mathrm{P}<0.001$ ) and the municipalities without a hemodialysis center are not homogeneously distributed in the country $\left(\chi^{2}=36.548\right.$; $\mathrm{P}<0.001$ ) (Table 1).

The 63 municipalities with a hemodialysis center represent an average population of 100,033 inhabitants $(S D=93,168)$. In these municipalities there is, on average, one center per 72,727 inhabitants $(S D=69,031)$. In the univariate analysis, a statistical difference was found between the population of municipalities with and without a hemodialysis center (U Mann-Whitney = 1247; P <0.001). Buying power percentage per capita in municipalities without a hemodialysis center is $68.6 \%(\mathrm{SD}=17.5 \%)$, whilst buying power percentage in municipalities with a hemodialysis center is $100.0 \% \quad(\mathrm{SD}=29.9 \%)$ (U Mann-Whitney = 2116; $\mathrm{P}<0.001$ ). Consumption of electricity per inhabitant in municipalities without a hemodialysis center is $4.189 \mathrm{kWh}(\mathrm{SD}=5.434)$, whereas consumption of electricity per inhabitant in municipalities with hemodialysis center is $4.920 \mathrm{kWh}$ $(\mathrm{SD}=2.682)$ (U Mann-Whitney = 3990; $\mathrm{P}<0.001)$.

The logistic analysis performed to predict the likelihood of a municipality having a hemodialysis center estimated $89.6 \%$ correctly. The Hosmer and Lemeshow test showed that the model was approaching significance $(P=0.07)$ and the Nagelkerke $R^{2}$ approach shows that the model explains $64.5 \%$ of the variance (Table 2). Variance inflation factor for variables in the model ranged from 1.1 to 2.3 , demonstrating the absence of multicollinearity. Only some NUTS-2 regions, population, and buying power percentage were predicting variables for the existence of a hemodialysis facility in a municipality. 
Table 1. Distribution of hemodialysis centers in Portugal mainland.

\begin{tabular}{|c|c|c|c|c|c|c|}
\hline & $\begin{array}{l}\text { North } \\
\text { average } \\
\text { (SD) }\end{array}$ & $\begin{array}{l}\text { Central } \\
\text { region }\end{array}$ & $\begin{array}{l}\text { Lisbon \& } \\
\text { Tagus Valley }\end{array}$ & Alentejo & Algarve & $\mathrm{P}$ \\
\hline Population & $3,745,236$ & $2,385,911$ & $2,808,414$ & 760,933 & 426,386 & \\
\hline Number of hemodialysis centers & 42 & 24 & 34 & 11 & 4 & \\
\hline Population per hemodialysis center & 89,172 & 99,413 & 82,600 & 69,176 & 106,597 & $<0.001 *$ \\
\hline $\begin{array}{l}\text { Population in municipalities lacking } \\
\text { hemodialysis center }\end{array}$ & $\begin{array}{r}20,513 \\
(19,863)\end{array}$ & $\begin{array}{r}17,367 \\
(13,697)\end{array}$ & $\begin{array}{r}53,778 \\
(22,221)\end{array}$ & $\begin{array}{r}10,6692 \\
(7,615)\end{array}$ & $\begin{array}{r}22,531 \\
(19,960)\end{array}$ & $<0.001 *$ \\
\hline Municipalities lacking hemodialysis center & $\begin{array}{r}60 \\
(69.8 \%)\end{array}$ & $\begin{array}{r}85 \\
(85.0 \%)\end{array}$ & $\begin{array}{r}5 \\
(27.8 \%)\end{array}$ & $\begin{array}{r}52 \\
(89.7 \%)\end{array}$ & $\begin{array}{r}13 \\
(81.3 \%)\end{array}$ & $<0.001 * *$ \\
\hline $\begin{array}{l}\text { Distance }(\mathrm{km}) \text { to hemodialysis center } \\
\text { in municipalities lacking one }\end{array}$ & $\begin{array}{r}28.3 \\
(15.1)\end{array}$ & $\begin{array}{r}31.3 \\
(16.4)\end{array}$ & $\begin{array}{l}14.2 \\
(8.6)\end{array}$ & $\begin{array}{r}39.4 \\
(19.5)\end{array}$ & $\begin{array}{r}30.3 \\
(17.2)\end{array}$ & $0.002 *$ \\
\hline $\begin{array}{l}\text { Travel time (min) to hemodialysis center in } \\
\text { municipalities lacking one }\end{array}$ & $\begin{array}{r}33.2 \\
(16.7)\end{array}$ & $\begin{array}{r}34.3 \\
(15.7)\end{array}$ & $\begin{array}{r}20.6 \\
(10.4)\end{array}$ & $\begin{array}{r}29.5 \\
(12.2)\end{array}$ & $\begin{array}{r}29.5 \\
(12.2)\end{array}$ & $0.04 *$ \\
\hline
\end{tabular}

*Kruskal-Wallis test; * $\chi^{2}$ test; $\mathrm{SD}=$ standard deviation.

The average distance for the inhabitants in one of the 215 municipalities without a hemodialysis center was $32.4 \mathrm{~km}$ ( $\mathrm{SD}=14.4 \mathrm{~km})$, with 1,393,770 inhabitants $(13.8 \%)$ living 30-60 min away from a hemodialysis center, and $145,551(1.5 \%)$ over $60 \mathrm{~min}$ away. Distance and travel times do not follow a homogeneous distribution in Portugal mainland (Table 1). The greatest "individual burden", i.e. the longest distance to be travelled to a hemodialysis center, occurs in the municipality of Barrancos, where an estimated two ESRD cases from a population of 1,730 inhabitants have to travel $101 \mathrm{~km}$ (94 min). The highest "popula-

Table 2. Factors predicting existence of hemodialysis center in a municipality ( $\mathrm{n}=278$; Nagelkerke $\left.\mathrm{R}^{2}=0.645\right)$.

\begin{tabular}{lrrr}
\hline Parameters & OR & $\begin{array}{c}95 \% \text { confidence } \\
\text { interval }\end{array}$ & P \\
\hline NUTS-2 & & - & - \\
$\quad$ North & 1 & $0.01-0.51$ & 0.011 \\
$\quad$ Algarve & 0.05 & $0.13-1.17$ & $\mathrm{~ns} *$ \\
$\quad$ Central region & 0.39 & $0.01-0.28$ & 0.002 \\
$\quad$ Lisbon \& Tagus Valley & 0.03 & $0.09-1.53$ & $\mathrm{ns*}$ \\
$\quad$ Alentejo & 0.37 & $1.31-1.92$ & $<0.001$ \\
& & $1.03-1.10$ & $<0.001$ \\
Population (10,000) & 159 & & $\mathrm{~ns}$ \\
Buying power percentage per & 106 & $1.00-1.00$ & \\
capita & & & \\
Electricity consumption & 100 & & \\
\hline
\end{tabular}

"ns = not significant tion burden" occurs in the municipality of Odemira, where 22 estimated ESRD cases, out of a population of 25,510 inhabitants, have to travel an average distance of $94 \mathrm{~km}$ (84 min) to the closest hemodialysis center. Figure 1 presents the distribution of population and distance to the closest hemodialysis center in municipalities lacking one. Portuguese policy makers reports state that one dialysis center, either public or private, is warranted for a population of every 70,000 inhabitants (Natario et al., 2003), However, we found four municipalities with total populations over 70,000 inhabitants lacking hemodialysis centers.

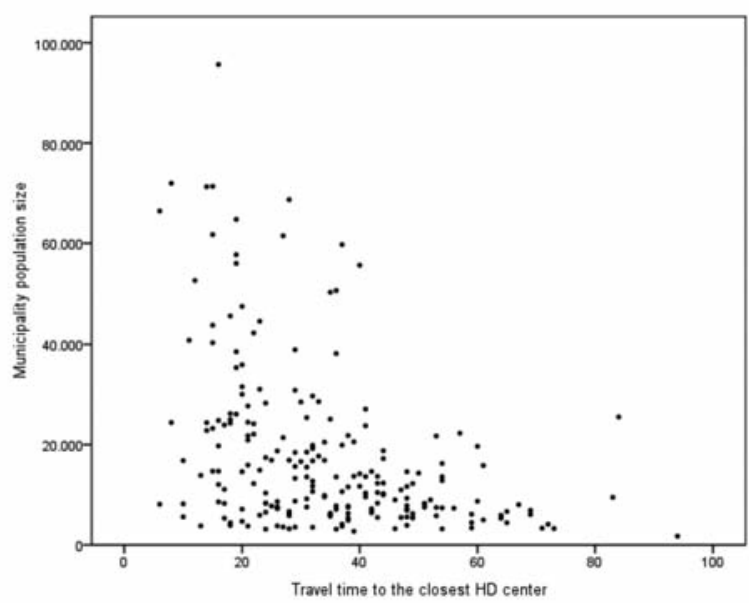

Fig. 1. Scatter plot representing population against time to the closest center in municipalities without hemodialysis center. 


\section{Application of the model}

Distribution maps of the "population burden" and "individual burden" are presented in Figures 2 and 3, respectively. Aggregating the weights for "individual burden" and "population burden" resulted in 12 municipalities with the maximum weighting (score = 8), depicted in black in the "composite burden" map (Fig. 4). The establishment of 12 new centers in these areas would result in an average of 82,332 people per center in Portugal mainland. The new total of 123 hemodialysis centers would present the following population ratios per region: North 87,099 people per hemodialysis center, Central region 85,211, Lisbon \& Tagus Valley 82,600, Alentejo 42,274, and Algarve 106,597. None of these 12 new facilities would be established in major urban areas.

If these 12 new hemodialysis centers were established, there would be a reduction of municipalities lacking a center from $215(77.3 \%)$ to $203(73.0 \%)$. These new centers would not only benefit the 12 municipalities, but also serve a total of 34 other municipalities currently lacking such facilities, as they would become closer to these news centers than the existing ones (Table 3). The average distance for

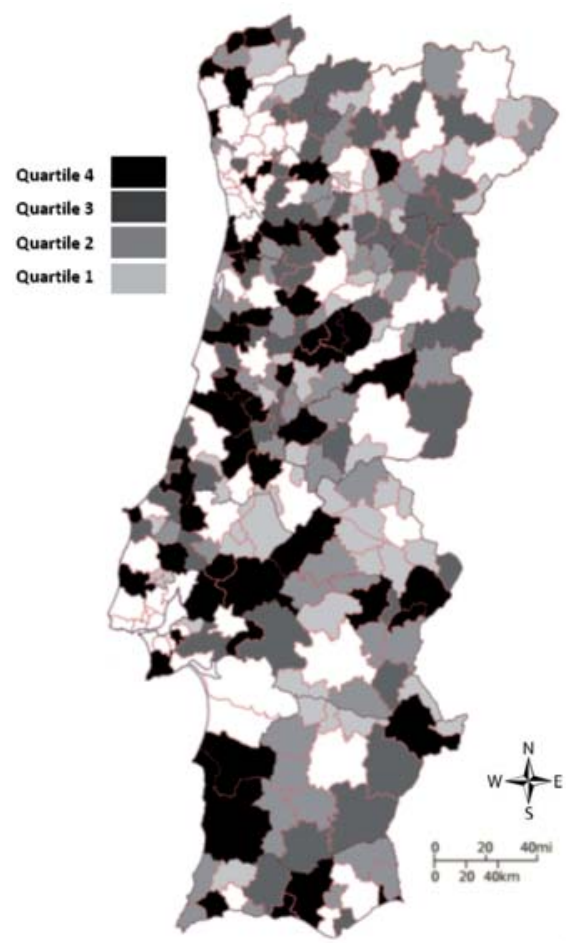

Fig. 2. "Population burden" map. White = municipalities with hemodialysis center. Shading grade goes from light gray $=$ first quartile to black $=$ fourth quartile. (Percentile $25=141,990$ min*inhabitants, median $=413,865$ min*inhabitants, and percentile $75=615,636 \mathrm{~min} *$ inhabitants).

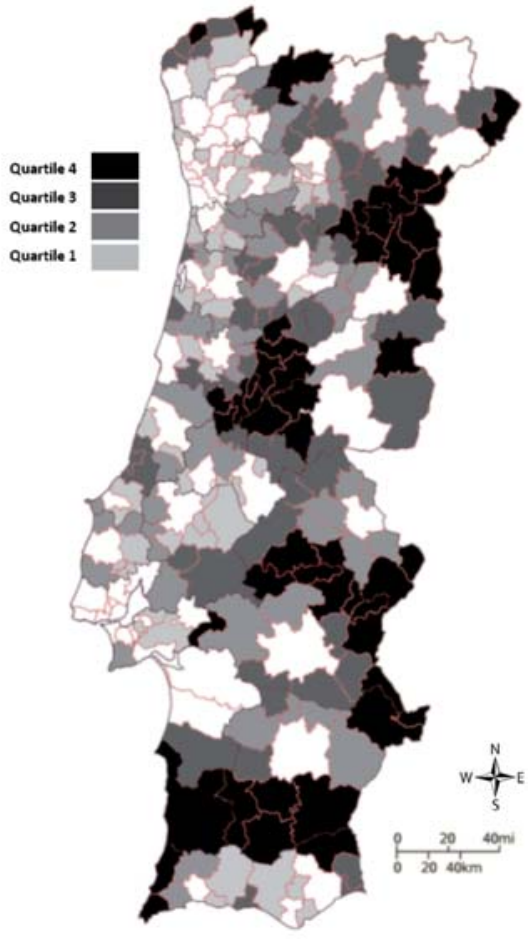

Fig. 3. "Individual burden" map. White = municipalities with hemodialysis center. Shading grade goes from light gray $=$ first quartile to black $=$ fourth quartile (Percentile $25=21 \mathrm{~min}$, median $=32 \mathrm{~min}$, percentile $75=44 \mathrm{~min}$ ).

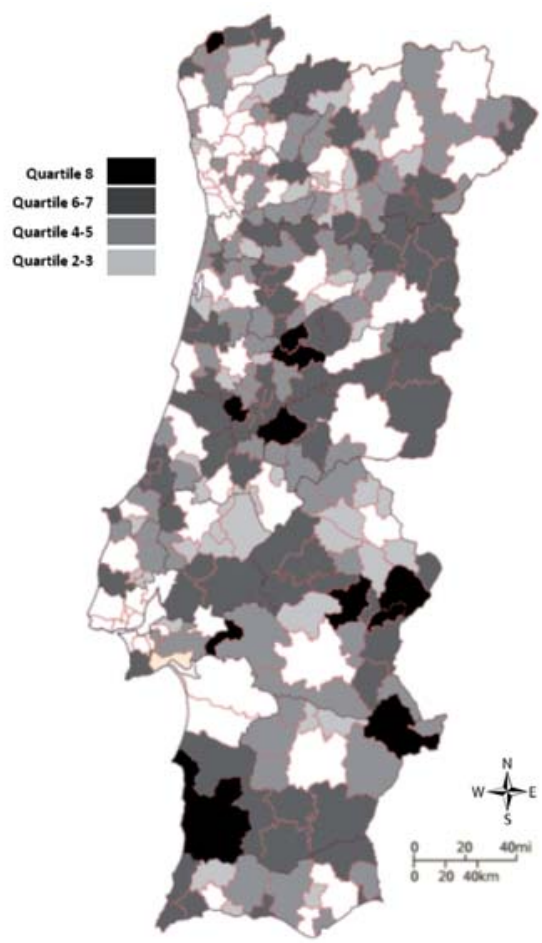

Fig. 4. "Composite burden" map. White = municipalities with hemodialysis center. Shading grade goes from light gray $=2-3$ weight score, moderate gray $=4-5$ weight score and dark gray $=$ 6-7 weight score. Black areas represent 12 municipalities reaching maximum weight (score $=8$ ). 
Table 3. Locations for new hemodialysis facilities resulting from the application of the model.

\begin{tabular}{lccr}
\hline Municipality & Population & $\begin{array}{c}\text { Additional } \\
\text { municipalities } \\
\text { served* }\end{array}$ & $\begin{array}{c}\text { Total population } \\
\text { served and } \\
\text { (estimated cases)** }\end{array}$ \\
\hline Valença & 14,305 & 5 & $78,217(69)$ \\
Ansiao & 13,591 & 6 & $118,119(103)$ \\
Tabua & 12,331 & 4 & $65,205(57)$ \\
Arganil & 12,799 & 2 & $21,661(19)$ \\
Serta & 15,841 & 3 & $39,860(35)$ \\
Sines & 13,681 & 1 & $43,379(38)$ \\
Odemira & 25,510 & 1 & $31,061(27)$ \\
Elvas & 22,279 & 1 & $30,570(27)$ \\
Estremoz & 14,658 & 3 & $26,387(23)$ \\
Vendas Novas & 12,225 & 2 & $36,014(32)$ \\
Vila Viçosa & 8,694 & 3 & $29,011(25)$ \\
Moura & 16,233 & 3 & $28,454(25)$ \\
\hline
\end{tabular}

*Municipalities served by the new center must lack a hemodialysis center of their own and also be located closer to the new center than to any other existing ones; * $*$ the number of estimated cases were calculated using prevalence data from 2008.

inhabitants in one of the resulting 203 municipalities without a hemodialysis center would be $26.6 \mathrm{~km}$ $(\mathrm{SD}=13.6 \mathrm{~km})$ instead of the previous $32.4 \mathrm{~km}$ $(\mathrm{SD}=14.4 \mathrm{~km})$, which represents $18 \%$ reduction in travel distance. With these new centers, the greatest 'individual burden' would now occur in the municipality of Penedono, where an estimated three ESRD cases out of a population of 3,322 inhabitants would still have to travel $58 \mathrm{~km}(71 \mathrm{~min})$ to reach the closest hemodialysis center. As a result of applying the model, only six municipalities, amounting to 34,800 people, would remain over $60 \mathrm{~min}$ way from the hemodialysis center, which contrasts positively with the previous number of 145,551 people. The highest "population burden" would occur in the municipality of Alcobaça where the estimated 50 ESRD cases, out of a population of 55,643 inhabitants, would have to travel an average distance of $32 \mathrm{~km}(40 \mathrm{~min})$ to reach the closest hemodialysis center.

\section{Discussion}

Finding a ratio of one center per approximately 91,000 inhabitants suggests that the criteria published by the Portuguese Ministry of Health (Natario et al., 2003) have not been fully met. The estimated ratio mentioned in this official report indicates that Portugal mainland would need 145 centers rather than the existing 111 . The fact that there is a concentration of hemodialysis centers in Coimbra, Oporto, and Lisbon, the three major urban areas, results in much lower population ratios than in the rural areas. This concentration is clearly demonstrated in the Lisbon \& Tagus Valley region (the most populated NUTS-2) where the four smallest municipalities (out of 18), each with more than 50,000 people, lack facilities for hemodialysis. Furthermore, Lisbon \& Tagus Valley has a population of 2,808,414 and 34 hemodialysis centers, concentrating $71 \%$ of those units in four municipalities comprising only $36 \%$ of the population of that area. This focus on the cities has also been reported in other studies demonstrating geographic inequities in the Portuguese health system, such as the uneven distribution of hospitals (Oliveira and Bevan, 2003) and facilities providing care for the elderly (Santana, 2000). The multivariate analysis revealed an association with "buying power percentage" but none with "electricity consumption", which could be interpreted as correlation with welfare but not with industrialization. The fact that the three major cities are in the top-10 buying power percentage bracket in Portugal, but none of them in the top-10 electricity consumption category, confirms the city-focused distribution. Association of hemodialysis facilities with welfare should be a major concern for policy makers, as ESRD is usually associated with social disadvantage (Rodriguez et al., 2007; Ward, 2008).

Although Portugal is in better position regarding travel time compared to other European countries, we found locations nearly $100 \mathrm{~km}$ away from a hemodialysis center, namely in Barrancos $(101 \mathrm{~km})$ and in Odemira $(94 \mathrm{~km})$ with an estimated travel time of 94 and $84 \mathrm{~min}$, respectively. According to the current hemodialysis prevalence (nearly 0.9 per 1,000 people), the $1.5 \%$ inhabitants living $60 \mathrm{~min}$ away from a center represent a total of 130 patients. Portuguese law dictates that transport for patients from their home to the hemodialysis center must be provided by the Government but there is no mention to the maximum distance allowed for travel or the time spent in transport. Regardless the total number of hemodialysis facilities, the results showed that travel time for patients is not homogeneously distributed across the different regions of the country. This uneven distribution could be considered as a health inequity following the definition of the WHO (http://www.who.int/hia/about/glos/en/index1.html).

Some geospatial studies used the residential positions of existing hemodialysis patients to estimate the best location for new hemodialysis facilities. However, using prevalence data like that may not be the best option since: (i) there is a long time lag before a new facility will be operational; (ii) regional prevalence 
may change rapidly because there may not exist any association between prevalence and incidence at any given time; and (iii) the use of health care increases when they become available and better situated (Turnbull et al., 2008). This has indeed been reported for renal replacement therapy (White et al., 2006). Thus, when no evidence-based reasons were identified for the diversity of ESRD prevalence in diverse geographic areas, probabilistic methods should be used to establish the best localization for a new facility. From a population point of view, any individual in the country, ceteris paribus, has the same probability of needing renal replacement therapy in the future, and all should count equally in a probabilistic estimation for the best future position of the new facility.

We suggest a model to identify the optimal placement for new hemodialysis facilities based on a probabilistic approach that takes into account equal likelihood for individuals in different geographic areas, ceteris paribus, to become renal replacement therapy candidates. This model builds a composite map for the best location options by aggregating two maps representing individual needs and population needs for hemodialysis centers. The "population burden" represents the logistic and economic costs charged to the National Health System to transport patients undergoing renal replacement therapy, whereas the "individual burden" represents the potential impact on quality of life and satisfaction of each individual due to travel time to the hemodialysis facility.

This model can be used to generate debate on potential policies for the localization of renal replacement therapy facilities in any country, with the ultimate aim of improving the quality of care for patients with ESRD. To date, no specific regulations exist determining the geographical distribution of hemodialysis centers in Portugal, as the ones passed to ensure adequate access to community pharmacies. The application of this model to the Portuguese situation resulted in 12 locations where new hemodialysis centers could be established. Presently, in Portugal this debate is under discussion and it has been promised that 15 new hemodialysis centers would open by the end of 2012 (Portuguese Renal Foundation, 2009).

As a limitation of our study, a sensitivity analysis should be carried out to assess the effect of these different weighting options. However, policy makers and health care planners from different countries could consider using this model by assigning different weights to the scores resulting from the "individual burden" and "population burden" analysis. Increasing the weights of individual burden, would result in plac- ing new hemodialysis centers in remote areas which are far away from the existing ones. On the other hand, increasing the weight of population burden would place the new hemodialysis facilities in quite populated areas currently without a center. Balancing these two components together, would address individuals' needs bearing in mind the system sustainability. Additionally, a potential improvement of the model would encompass adjusting the probability of needing hemodialysis in the future with reliable data from the distribution of diabetes and hypertension prevalence. This adjustment would only be useful if these prevalence data were not affected by other inequities in the health care provision throughout the country.

\section{Acknowledgements}

We would like to thank Fundaçao para a Ciencia e a Tecnologia, Ministry of Science, Technology and Higher Education, Portugal, for supporting this work (Doctoral Grant reference number SFRH/BD/43999/2008).

\section{References}

Boyle PJ, Kudlac H, Williams AJ, 1996. Geographical variation in the referral of patients with chronic end stage renal failure for renal replacement therapy. Q J Med 89, 151-157.

Brammah A, Young G, Allan A, Robertson S, Norrie J, Isles C, 2001. Haemodialysis in a rural area: a demanding form of treatment. Health Bull (Edinb) 59, 294-299.

de Macedo ME, Lima MJ, Silva AO, Alcantara P, Ramalhinho V, Carmona J, 2007. Prevalence, awareness, treatment and control of hypertension in Portugal. The PAP study. Rev Port Cardiol 26, 21-39.

ERA-EDTA, 2002. European Best Practice Guidelines for Haemodialysis (Part 1). II.5 Dialysis schedules. Nephrol Dial Transplant 17, 25-31.

European Comission, 2003. Regulation (EC) No 1059/2003 of the European Parliament and of the Council of 26 May 2003 on the establishment of a common classification of territorial units for statistics (NUTS). Official Journal of the European Union L 154, 1-41.

Hagren B, Pettersen IM, Severinsson E, Lutzen K, Clyne N, 2005. Maintenance haemodialysis: patients' experiences of their life situation. J Clin Nurs 14, 294-300.

Harwood L, Locking-Cusolito H, Spittal J, Wilson B, White S, 2005. Preparing for hemodialysis: patient stressors and responses. Nephrol Nurs J 32, 295-302.

Hernandez-Avila JE, Santos-Luna R, Palacio-Mejia LS, SalgadoSalgado AL, Rios-Salgado VH, Rodriguez-Lopez MH, Sepulveda-Amor J, 2010. (Automated geospatial model for health services strategic planning). Salud Publica Mex 52, 432- 
446 (in Spanish).

INE, 2009a. Consumo de energia eléctrica por habitante (kWh/hab.) por local de residência.

INE, 2009b. Estimativas provisórias de população residente Portugal, NUTS II, NUTS III e Municípios - 2007.

INE, 2009c. Poder de compra per capita por localização geográfica.

Krespi R, Bone M, Ahmad R, Worthington B, Salmon P, 2004. Haemodialysis patients' beliefs about renal failure and its treatment. Patient Educ Couns 53, 189-196.

Lwasa S, 2007. Geospatial analysis and decision support for health services planning in Uganda. Geospat Health 2, 29-40.

MacGregor MS, Campbell J, Bain M, Isles CG, Simpson K, 2005. Using geographical information systems to plan dialysis facility provision. Nephrol Dial Transplant 20, 1509-1511.

Michelin, 2009. Itineraires ViaMichelin: Plans et itineraires France et Europe.

Moist LM, Bragg-Gresham JL, Pisoni RL, Saran R, Akiba T, Jacobson SH, Fukuhara S, Mapes DL, Rayner HC, Saito A, Port FK, 2008. Travel time to dialysis as a predictor of healthrelated quality of life, adherence, and mortality: the Dialysis Outcomes and Practice Patterns Study (DOPPS). Am J Kidney Dis 51, 641-650.

Natario A, Morais Sarmento A, Carrera F, Boquinhas JM, Campos M, Trigo MC, Proenca MJ, Ponce P, 2003. Hospital referring network of nephrology, Ministry of Health.

NHS-Scotland, 2002. Adult Renal Services. Clinical Standards Board for Scotland, Edinburgh, Scotland, UK.

NKF, 2006. Clinical practice guidelines for hemodialysis adequacy, update 2006. Am J Kidney Dis 48, S2-90.

Oliveira MD, Bevan G, 2003. Measuring geographic inequities in the Portuguese health care system: an estimation of hospital care needs. Health Policy 66, 277-293.

Ong ME, Chiam TF, Ng FS, Sultana P, Lim SH, Leong BS, Ong
VY, Ching Tan EC, Tham LP, Yap S, Anantharaman V, 2010. Reducing ambulance response times using geospatial-time analysis of ambulance deployment. Acad Emerg Med 17, 951-957.

Portuguese Renal Foundation, 2009. Renal Foundation reports 15 new dialysis centers until 2012. Publico, 8-Sept-2009.

Roderick P, Clements S, Stone N, Martin D, Diamond I, 1999. What determines geographical variation in rates of acceptance onto renal replacement therapy in England? J Health Serv Res Policy 4, 139-146.

Rodriguez RA, Sen S, Mehta K, Moody-Ayers S, Bacchetti P, O'hare AM, 2007. Geography matters: relationships among urban residential segregation, dialysis facilities, and patient outcomes. Ann Intern Med 146, 493-501.

Santana P, 2000. Ageing in Portugal: regional inequities in health and health care. Soc Sci Med 50, 1025-1036.

Sayin A, Mutluay R, Sindel S, 2007. Quality of life in hemodialysis, peritoneal dialysis, and transplantation patients. Transplant Proc 39, 3047-3053.

Sociedade Portuguesa de Nefrologia, 2009a. Centros de Nefrologia.

Sociedade Portuguesa de Nefrologia, 2009b. Gabinete de Registo do tratamento da Doença Renal Terminal.

Turnbull J, Martin D, Lattimer V, Pope C, Culliford D, 2008. Does distance matter? Geographical variation in GP out-ofhours service use: an observational study. Br J Gen Pract 58, 471-477.

Ward MM, 2008. Socioeconomic status and the incidence of ESRD. Am J Kidney Dis 51, 563-572.

White P, James V, Ansell D, Lodhi V, Donovan KL, 2006. Equity of access to dialysis facilities in Wales. Q J Med 99, 445-452. White SL, Chadban SJ, Jan S, Chapman JR, Cass A, 2008. How can we achieve global equity in provision of renal replacement therapy? Bull World Health Organ 86, 229-237. 